\title{
Analysis of Process Parameters for Different Material Pairs of Mechanically Lined CRA Pipes Manufactured by Thermal-Hydraulic Expansion Process
}

\author{
Jiansha DONG, Fahrettin OZTURK*, Ana NIETO, Tianye GUO, Firas JARRAR, Jamal Y. SHEIKH-AHMAD
}

\begin{abstract}
Mechanically lined corrosion resistant pipes are produced by establishing a sufficiently high residual contact pressure (gripping force) between a corrosion resistant liner and a steel outer pipe. The most effective way to achieve such high contact pressure is by the thermal-hydraulic expansion manufacturing process. In this study, simulation of the thermal-hydraulic expansion process of mechanically lined corrosion resistant pipes is performed using the finite element method. The effects of process parameters such as process temperature, hydraulic pressure, and cooling rates for different material pairs of mechanically lined corrosion resistant pipes are investigated. Results reveal that both the water- and air-cooling rates have negligible influence on the magnitude of residual contact pressure. The furnace temperature is proved to be the governing factor to obtain high residual contact pressure for the material pairs N08825/X65 and N08031/X65. However, for the material pair 304/X65, increasing the temperature difference by reducing the hydraulic loading and unloading time durations as much as possible is the most effective way to increase the residual contact pressure.
\end{abstract}

Keywords: gripping force; mechanically lined CRA pipe; mechanically sleeved CRA pipe; residual contact pressure; thermal-hydraulic expansion

\section{INTRODUCTION}

The increase in the global energy demand has led to the exploration of reservoirs in harsher environments or with more corrosive fluids that require the use of pipes equipped with corrosion resistant alloys (CRA) [1-3]. Due to the high cost of these materials, double walled pipes have been developed as cost efficient alternatives to solid CRA pipes [4, 5]. Such kind of pipes consists of a corrosion resistant liner pipe bonded to a steel outer pipe, which is able to withstand the pressure and environmental conditions. The outer pipe is a normal carbon steel pipe that supports mechanical loads [6,7].

The high initial capital cost of double walled pipes is justified by their lower maintenance and operating costs [8]. Depending on the way the liner and the outer pipes are joined together, the double walled pipes can be classified into two main groups: metallurgically and mechanically bonded pipes. Compared with the mechanically bonded pipes, metallurgically bonded pipes, also known as clad pipes, are expensive to manufacture and offer limited material combinations. Therefore, the mechanically lined pipes are considered the preferred choice for transporting corrosive hydrocarbons [9].

Mechanically lined CRA pipes can be manufactured using two different methods: hydraulic and thermalhydraulic expansion processes [10]. In the hydraulic expansion manufacturing process, internal pressure is applied to the liner pipe after its insertion into the outer pipe. The hydraulic pressure causes the liner pipe to expand radially and push the outer pipe in the same direction. As the liner pipe expands, its material yields due to excessive hoop stresses while the outer pipe is deformed only in the elastic range. Upon pressure release, the outer pipe tries to retain its initial diameter, however its relaxation is constrained by the expanded liner pipe. This constraint creates a gripping force (residual contact pressure) between the liner and the outer pipes. This residual contact pressure is an important factor in manufacturing mechanically lined pipes. The higher the residual contact pressure the stronger the bonding between the two materials and the better the performance of the corrosion resistant pipe. For a given pair of liner and outer pipe materials, the residual contact pressure is mainly a function of the applied hydraulic pressure, the elastic properties of the two materials and the dimensions of the two pipes [11]. Dezhi et al. studied [12] the thermal load and strength of the lined steel pipe. They developed a mechanical model to calculate the thermal strength. The correlations between the thermal strength, residual contact pressure, and wall thickness of the inner pipe were obtained using the proposed model.

The thermal-hydraulic expansion process is different from the hydraulic expansion process which was explained previously [13]. The outer pipe is heated to a certain high temperature in a furnace before inserting a liner pipe. Afterwards, hydraulic pressure is applied to expand the liner pipe. Then following the unloading of the pressure, there is a cooling step to finish the whole manufacturing process. This thermal-hydraulic expansion manufacturing process is schematically illustrated in Fig. 1.

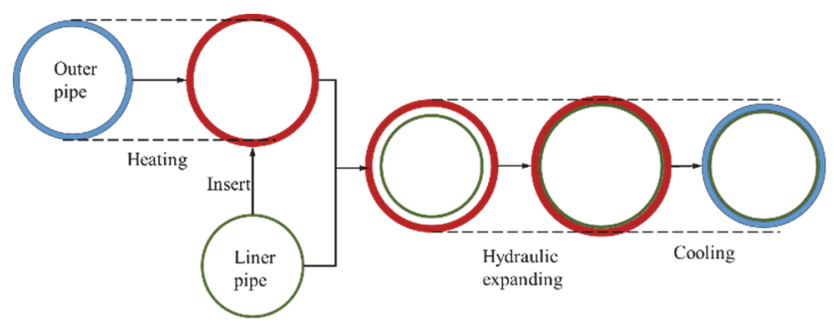

Figure 1 Schematic representation of the thermal-hydraulic expansion manufacturing process of a mechanically lined CRA pipe

Focke [14] analyzed the thermal-hydraulic manufacturing process using both analytical and finite element methods. The 2-D cross-sectional analytical model was verified by a finite element model which modelled only $10^{\circ}(1 / 36)$ of the liner and the outer pipe. About $10 \%$ difference was found through comparison, which might have resulted from material modelling simplification in the analytical model. Dimensions of the liner and the outer pipes were concluded as important parameters that could affect the residual contact pressure through sensitivity analysis. However, the effect of other process parameters on the contact pressure has not been fully understood. Therefore, in order to reach a better understanding of the 
thermal-hydraulic manufacturing process of the mechanically lined CRA pipes, a 2-D axisymmetric finite element model was developed in this study. The effects of several process parameters, including the process temperature, hydraulic pressure, and cooling rates for three different material pairs were simulated and results were compared.

\section{FINITE ELEMENT MODEL}

Finite Element Analysis (FEA) was mainly used in this study to investigate the thermal-hydraulic expansion manufacturing process and evaluate the effects of key process parameters for different material pairs of the mechanically lined CRA pipes on the residual contact pressure. The developed model is intended to be used for design purposes. The commercially available finite element software ABAQUS ${ }^{\mathrm{TM}}$ was used to develop the numerical models in this study.

The following assumptions were made in the analysis:

1) The constituent pipes are made of homogeneous and isotropic materials, their diameters and thicknesses are uniform.

2) The constituent pipes are initially concentric and they remain concentric during the thermal-hydraulic expansion process.

3) Considering the strain hardening of the liner pipe during the process, plastic properties of the liner material are based on the true stress - true strain curves measured in the tensile tests from the work of Focke [8].

4) The Bauschinger's effect is neglected when considering the reverse yielding of the liner pipe.

5) The temperature of the entire outer pipe equals that of the furnace chamber temperature during the heating process. In addition, the internal surface of the liner pipe is kept equal to the cooling water temperature during the cooling process. The temperature rise of the cooling water is neglected.

6) Heat conduction is considered between the two pipes only when they come in contact with each other.

The geometric parameters and material properties of both pipes, the liner and the outer, are summarized in Tab. 1. Moreover, the experimental true stress - true strain curves of the liner pipe materials, based on the data from [8] are shown in Fig. 2. This data is particularly important because the liner pipe undergoes plastic deformation during the thermal-hydraulic expansion process. Calculation of the plastic strain component is a critical part of the analysis of the pipe forming process.

Table 1 Geometric parameters and material properties of the corrosion resistant pipes

\begin{tabular}{|c|c|c|c|c|}
\hline & \multicolumn{3}{|c|}{ Liner Pipe } & $\begin{array}{c}\text { Outer } \\
\text { Pipe }\end{array}$ \\
\hline Outer Diameter, $D / \mathrm{mm}$ & \multicolumn{3}{|c|}{582.6} & 610 \\
\hline Thickness, $t / \mathrm{mm}$ & \multicolumn{3}{|c|}{4} & 12.7 \\
\hline Material Type & N08031 & N08825 & 304 & X65 \\
\hline $\begin{array}{c}\text { Young's Modulus, } E / \\
\mathrm{GPa}\end{array}$ & 198.1 & 192.21 & 193.19 & 200 \\
\hline Poisson's Ratio, $v$ & 0.27 & 0.27 & 0.27 & 0.3 \\
\hline Yield strength, $\sigma_{y} / \mathrm{MPa}$ & 435 & 353 & 294 & - \\
\hline $\begin{array}{c}\text { Thermal Expansion } \\
\text { Coefficient }, \alpha / \times 10^{-5} /{ }^{\circ} \mathrm{C}\end{array}$ & 1.4 & 1.4 & 1.6 & 1.3 \\
\hline
\end{tabular}

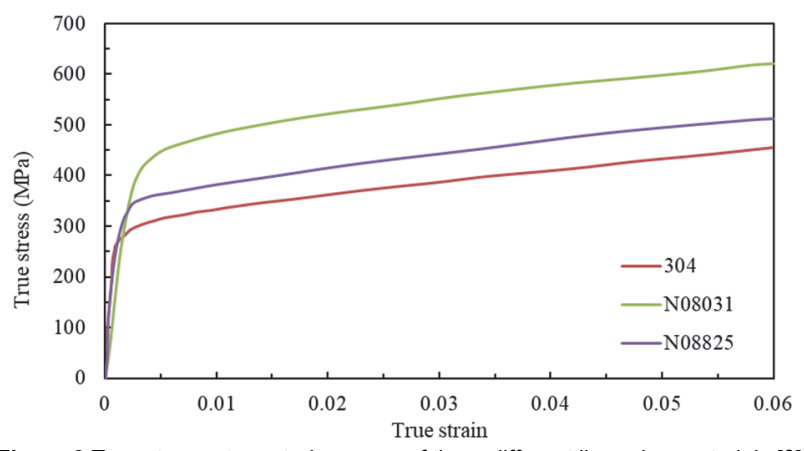

Figure 2 True stress - true strain curves of three different liner pipe materials [8]

The expansion forming process of the corrosion resistant pipe is a nonlinear elastoplastic, coupled thermomechanical problem. 2-D planar deformable type parts were employed to model the both pipes. Owing to the axisymmetric characteristic of the geometry and loading conditions, the problem can be simplified to a 2-D axisymmetric model as shown in Fig. 3. The 8-node axisymmetric thermally coupled reduced integration element CAX8RT was selected to build the numerical model. In terms of the boundary conditions, the upper and the lower end faces of the liner pipe were constrained in the directions (U2 = UR3 =0). Besides, YSYMM (degrees of freedom $\mathrm{U} 2=\mathrm{UR} 3=0$ ) was applied to the middle section of the outer pipe, since the outer pipe can deform in the axial direction freely. By conducting a length sensitivity analysis, a $100 \mathrm{~mm}$ was shown capable of obtaining accurate simulation results. Finally, through a mesh convergence study, 400 and 75 elements were used for meshing the liner and the outer pipes, respectively.

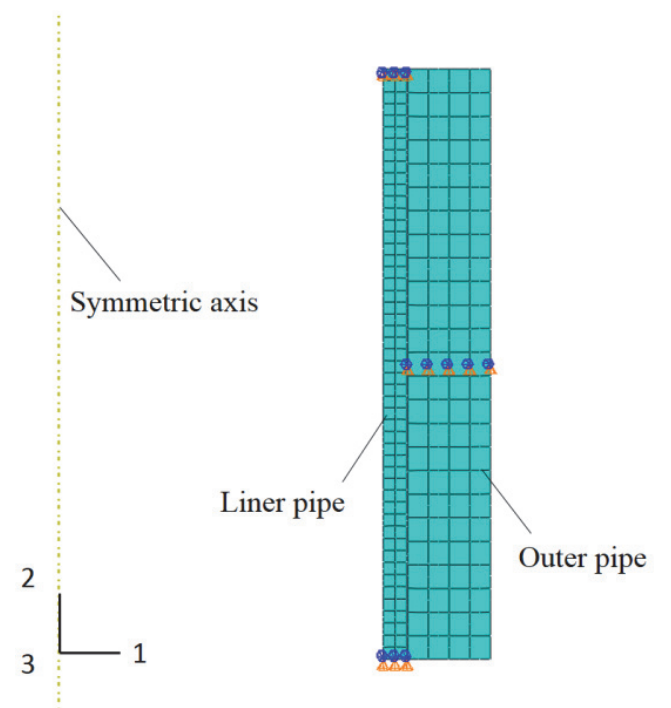

Figure 3 A 2-D axisymmetric model of the corrosion resistant pipe

Five analysis steps were defined in the finite element model corresponding to the practical procedure of the thermal-hydraulic expansion process of the corrosion resistant pipe. These steps are summarized as follows:

Step 1: Heating up the outer pipe. In the initial step, the temperatures of both the liner and the outer pipes are predefined as the room temperature $\left(25^{\circ} \mathrm{C}\right)$. Then in Step 1 , a temperature boundary condition is applied at the external surface of the outer pipe to heat up the entire outer pipe. 
Step 2: Hydraulic expansion. After the entire outer pipe is heated up to the desired temperature, the hydraulic pressure is applied on the internal surface of the liner pipe in Step 2. The liner pipe will expand until it touches the outer pipe and the heat will be transferred due to the temperature difference between the liner and the outer pipes. Meanwhile, both pipes will continue expanding together to the maximum hydraulic pressure. The contact between the external surface of the liner pipe and the internal surface of the outer pipe followed the surface-tosurface ABAQUS ${ }^{\mathrm{TM}}$ algorithm.

Step 3: Unloading the hydraulic pressure. In this step, while the outer pipe is kept at the furnace temperature, the hydraulic pressure is brought down to zero. The conduction between the two pipes is maintained when the liner pipe is still in contact with the outer pipe tightly due to the plastic deformation of the liner pipe.

Step 4: Water cooling. In order to increase the cooling rate, after unloading the hydraulic pressure, cooling water is injected inside the liner pipe. Therefore, a surface film condition is defined on the internal surface of the liner pipe to let the liner temperature decrease quickly.

Step 5: Air cooling. Surface film conditions denoting the direct contact with air are applied on the internal surface of the liner pipe and the external surface of the outer pipe. The final step is to let the combined pipe cool down to the room temperature.

\section{MODEL VERIFICATION}

The proposed finite element model was verified by comparing the obtained results with those found in related study by Focke et al. [14]. The geometric parameters and material properties of the corrosion resistant pipe are summarized in Tab. 2.

Table 2 Geometric parameters and material properties for the case of

\begin{tabular}{|c|c|c|}
\hline & $\begin{array}{c}\text { Liner Pipe } \\
\text { (Inconel 625) }\end{array}$ & $\begin{array}{c}\text { Outer Pipe } \\
\text { (API L80) }\end{array}$ \\
\hline Outer Diameter, $D / \mathrm{mm}$ & 58.85 & 73 \\
\hline Thickness, $t / \mathrm{mm}$ & 2 & 7 \\
\hline Young's Modulus, $E / \mathrm{GPa}$ & 206.01 & 195 \\
\hline Poisson's Ratio, $v$ & 0.3 & 0.3 \\
\hline Yield strength, $\sigma_{y} / \mathrm{MPa}$ & 431.64 & - \\
\hline $\begin{array}{c}\text { Thermal Expansion } \\
\text { Coefficient, } \alpha / \times 10^{-5} \mathrm{C}^{-1}\end{array}$ & 1.4 & 1.16 \\
\hline
\end{tabular}

Regarding the plastic properties of the liner pipe, the true stress - true strain curve is shown in Fig. 4.

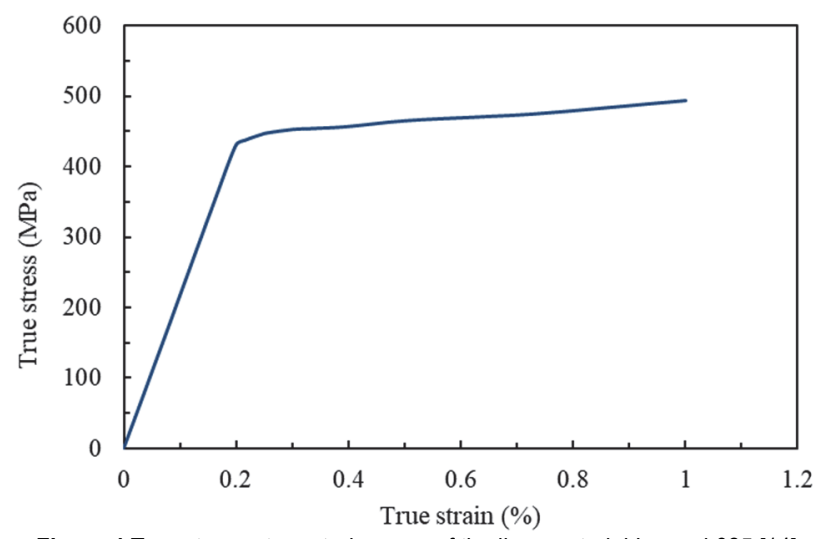

Figure 4 True stress - true strain curve of the liner material Inconel 625 [14]
In this case, the furnace temperature was set to $300{ }^{\circ} \mathrm{C}$, and the applied hydraulic pressure was $100 \mathrm{MPa}$. The temperature differential between the liner and the outer pipes is decided according to Eq. (1), which is used in the analytical analysis in the work of Focke et al. [14].

$\Delta T=T_{\mathrm{O}}-T_{\mathrm{L}} \cdot\left(\frac{\alpha_{\mathrm{L}}}{\alpha_{\mathrm{O}}}\right)$

where $T_{\mathrm{O}}$ and $T_{\mathrm{L}}$ are the average temperature of the outer and the liner pipes at the end of Step 3.

After the simulation, residual average hoop stresses of both the liner and the outer pipes were obtained. These stresses are required for the determination of the residual contact pressure between both pipes at the end of the manufacturing process.

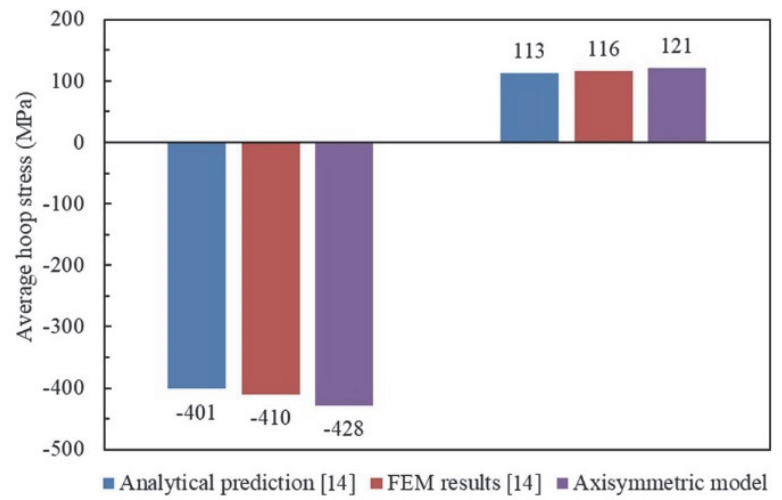

Figure 5 Results comparison of the average hoop stresses in the liner and the outer pipes

As shown in Fig. 5, the liner pipe has negative residual hoop stress which is in accordance with its compressive status. To the contrary, the outer pipe is under tension and has positive residual hoop stress. The simulation results of the proposed models have been compared with the analytical predictions and the finite element results of Focke et al. [14]. The difference between the simulation results of the proposed model and the analytical predictions is $6.7 \%$ and $7.1 \%$, respectively for the liner and the outer pipes. Similarly, when compared with the simulation results from the work of Focke et al. [14], the difference becomes smaller, $4.4 \%$ and $4.3 \%$, respectively. One probable reason causing the difference between the analytical prediction and the simulation results is that the liner material was simplified and modelled as bi-linear elastic in the analytical model.

\section{SENSITIVITY ANALYSIS}

There is a prominent advantage for using the finite element software to simulate an engineering problem compared with setting up the experiment. It is relatively easier and cheaper to use the finite element software to change parameters and investigate their influence on the results. Therefore, a sensitivity analysis of the residual contact pressure between the liner and the outer pipes to the different parameters during the manufacturing process was carried out by the FEM model. 


\subsection{Process Temperature}

In the thermal-hydraulic expansion process, the temperature is an important process parameter that influences the performance of the corrosion resistant pipes. There are two temperature parameters that need to be investigated. One is the heated outer pipe temperature or the furnace temperature. The other one is the temperature differential between the liner and the outer pipes, which can be estimated by Eq. (2). It can be controlled by changing the time durations of hydraulic loading (Step 2) and unloading (Step 3).

$\mathrm{d} T=\frac{T_{\mathrm{O}}-T_{\mathrm{L}}}{T_{\mathrm{O}}}$

Under the condition of a $20 \mathrm{MPa}$ hydraulic pressure and a $50 \%$ temperature differential, the sensitivity of the residual contact pressure to the furnace temperature of different material pairs was investigated and shown in Fig. 6. We can see that, for each material pair, the residual contact pressure firstly increases with the increasing furnace temperature but then decreases after a limit point. Besides, the limit points for each material pair are different. For the material pairs 304/X65, N08825/X65, and $\mathrm{N} 08031 / \mathrm{X} 65$, the highest residual contact pressure can be obtained at around 250,350 , and $450{ }^{\circ} \mathrm{C}$, respectively. In addition, it is found by comparing Figs. 2 and 6 that a larger yield strength of the liner material contributes to obtaining higher residual contact pressure. Thus, in the manufacturing process of the corrosion resistant pipe, a higher furnace temperature is not always beneficial to increase the residual contact pressure. In addition, a high furnace temperature requires more energy and production cost. Therefore, it is better to determine the optimum outer pipe temperature in the design stage.

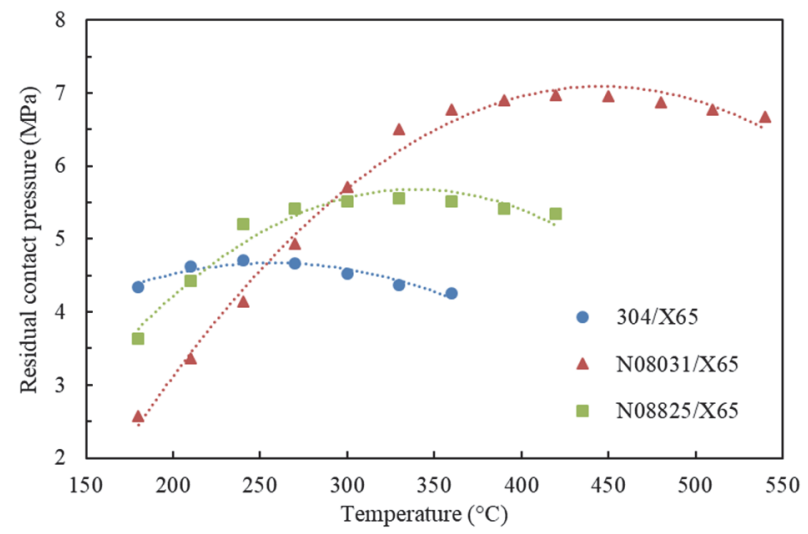

Figure 6 Sensitivity of the residual contact pressure to the furnace temperature

The sensitivity of the residual contact pressure to the temperature differential between the liner and the outer pipes is shown in Fig. 7. It is obvious that the residual contact pressure between the two pipes has the smallest value when the temperature differential equals zero. In this situation, the temperature of the liner pipe is raised up to reach that of the outer pipe. With the increasing of the temperature differential, the residual contact pressure increases almost linearly at first, then stays at the maximum value after reaching the critical temperature differential.
For different material pairs, the critical temperature differential varies between $40 \%$ and $60 \%$. It could be concluded that the lower the yield strength of the liner pipe material, the larger the temperature differential is needed in order to obtain the maximum residual contact pressure. However, during the practical manufacturing process, it is difficult to control the heating time of the liner pipe because the liner pipe temperature cannot be measured. Therefore, increasing the temperature differential between the two pipes could be helpful to increase the residual contact pressure. This can be achieved by decreasing the time durations as much as possible of the hydraulic loading and unloading.

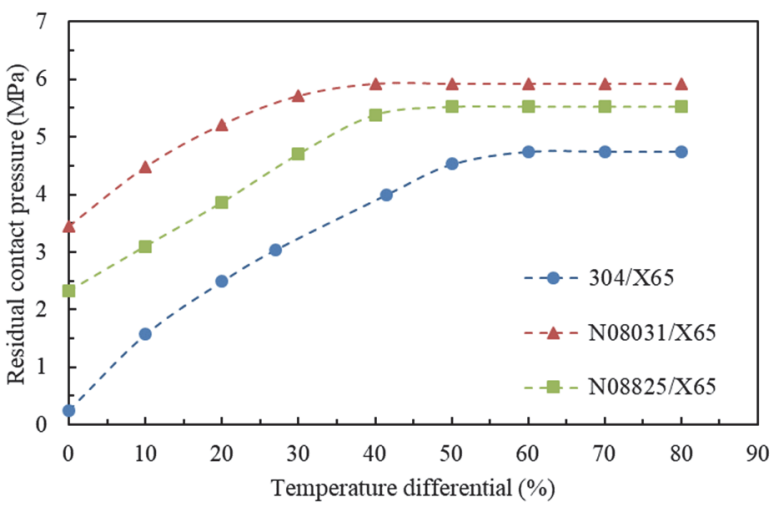

Figure 7 Sensitivity of the residual contact pressure to the temperature differential between the two pipes

\subsection{Hydraulic Pressure}

Under the manufacturing condition of $300{ }^{\circ} \mathrm{C}$ furnace temperature and $50 \%$ temperature differential, the sensitivity of the residual contact pressure to the hydraulic pressure was analyzed, and the results are shown in Fig. 8.

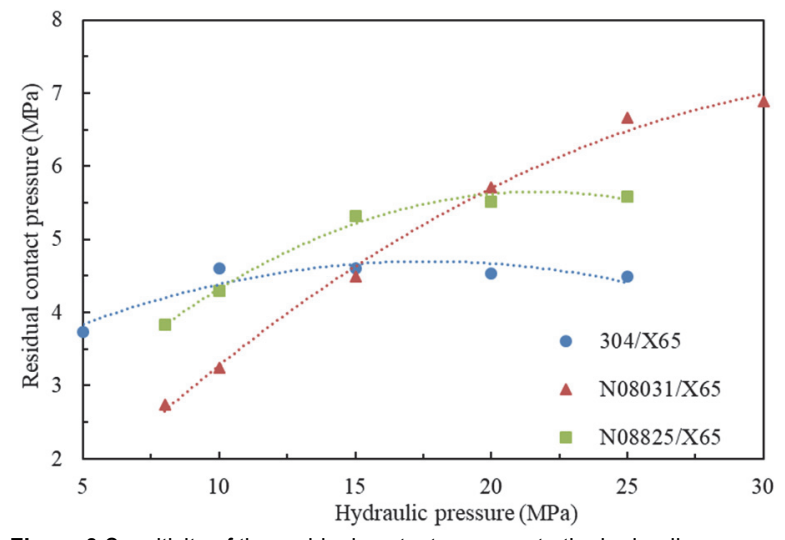

Figure 8 Sensitivity of the residual contact pressure to the hydraulic pressure

For each material pair, the hydraulic pressure lies between the minimum value under which the liner and the outer pipes can be combined and the maximum value when the outer pipe is about to yield. For the corrosion resistant pipe with the liner material 304, which has the lowest yield strength, hydraulic pressure has a minor influence on the residual contact pressure. A $150 \%$ increase in the hydraulic pressure from 10 to $25 \mathrm{MPa}$ could just cause a $2.6 \%$ change in the residual contact pressure. In addition, as the yield strength of the liner pipe material increases, larger contribution of the hydraulic pressure to the residual 
contact pressure is found. Obviously, the curve of the liner pipe material N08031 has the largest slope, with a $151.5 \%$ increment in the residual contact pressure through the applied hydraulic pressure range. Thus, for the liner material with small yield strength, such as $304,10 \mathrm{MPa}$ hydraulic pressure is enough to obtain the largest residual contact pressure. However, if the liner material has larger yield strength, better performance of the corrosion resistant pipe can be obtained by increasing the hydraulic pressure without causing yielding of the outer pipe.

\subsection{Cooling Rate}

The cooling rates of the corrosion resistant pipe in analysis of Step 4 and 5 can be controlled by adjusting the water and air film coefficients. In production, the water film coefficient can be increased by reducing the cooling water temperature and increasing the water flow rate at the internal surface of the liner pipe. In terms of increasing the air film coefficient, enhancing the air flow rate at both internal and external surfaces of the corrosion resistant pipe works.

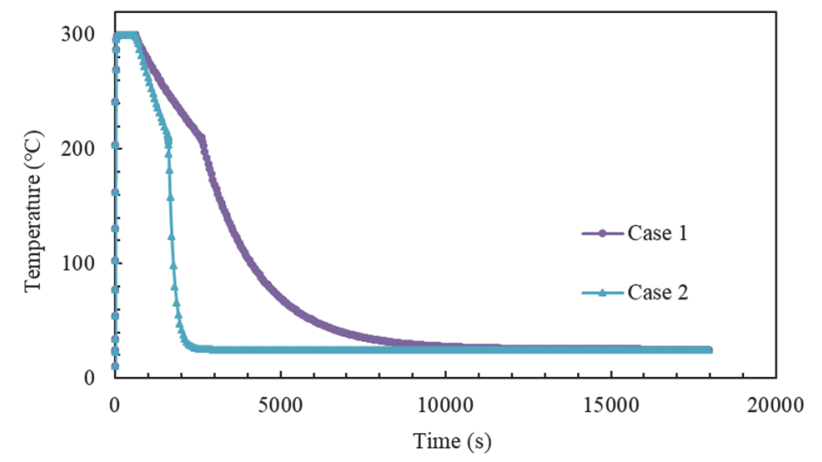

Figure 9 Temperature change of the outer pipe over time for different cases (Case 1: water film coefficient $=50 \mathrm{~W} / \mathrm{m}^{2}{ }^{\circ} \mathrm{C}$, air film coefficient $=20 \mathrm{~W} / \mathrm{m}^{2}{ }^{\circ} \mathrm{C}$; Case 2: water film coefficient $=400 \mathrm{~W} / \mathrm{m}^{2}{ }^{\circ} \mathrm{C}$, air film coefficient $=300 \mathrm{~W} / \mathrm{m}^{2}{ }^{\circ} \mathrm{C}$ )

Fig. 9 displays the changes in temperature of the outer pipes over the entire manufacturing time. Both cases were run under $300{ }^{\circ} \mathrm{C}$ furnace temperature, $50 \%$ temperature differential, and $20 \mathrm{MPa}$ hydraulic pressure. The difference is that Case 2 has larger water film coefficient and air film coefficient than Case 1. It can be seen from Fig. 9 that the slope magnitudes of Case 2 are larger than those of Case 1, which indicates that the cooling rate increases noticeably with the increase in the value of the film coefficient. Of course, they both decrease to the same desired temperature after enough cooling time.

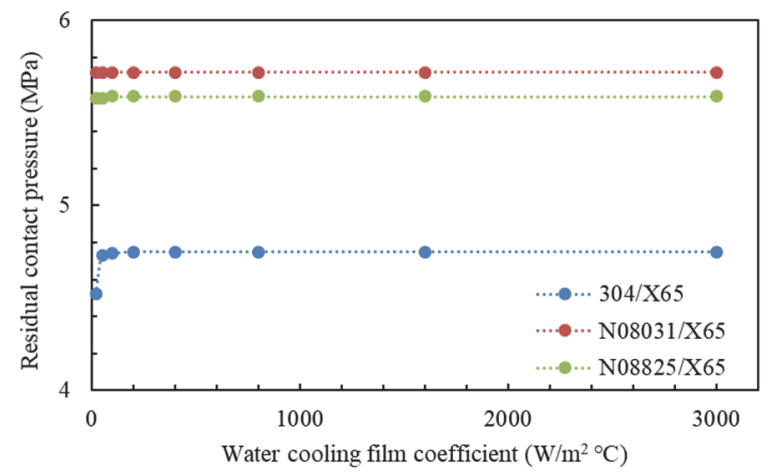

Figure 10 Sensitivity of the residual contact pressure to the water-cooling film coefficient in Step 4

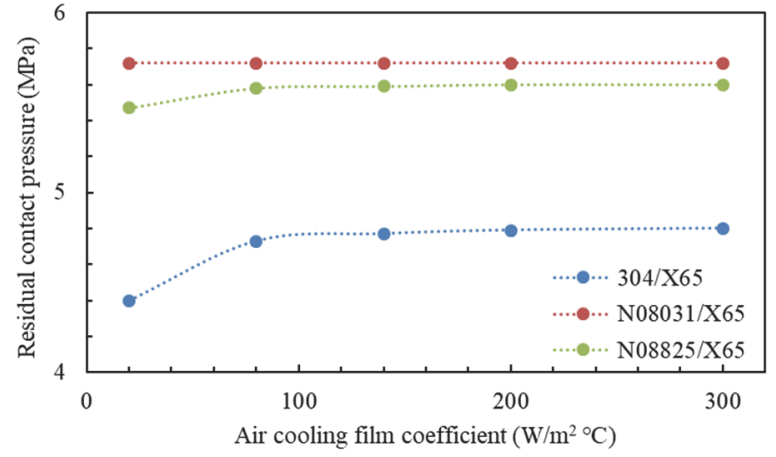

Figure 11 Sensitivity of the residual contact pressure to the air-cooling film coefficient in Step 5

Figs. 10 and 11 illustrate the influence of watercooling film coefficient (Step 4) and air-cooling film coefficient (Step 5) on the residual contact pressure, respectively. As the water-cooling film coefficient increases, for the corrosion resistant pipe with material pair $304 / \mathrm{X} 65$, the residual contact pressure increases at first but becomes stable soon. Besides, for the material pairs N08031/X65 and N08825/X65, the magnitudes of residual contact pressure are not influenced by the increasing watercooling film coefficient. Similar trends are also displayed in Fig. 11 as the air-cooling film coefficient increases.

In the sensitivity analysis, it was investigated that the impact of five process parameters on the residual contact pressure of the corrosion resistant pipes. The process parameters include the furnace temperature, temperature differential, hydraulic pressure, water cooling rate, and aircooling rate. For comparing the sensitivities of these parameters, a referential parameter - influence factor $\lambda$, which is the ratio of the percentage change in residual contact pressure to the percentage change in the parameter was introduced. The larger the value of $\lambda$ is, the more sensitive the residual contact pressure is to the parameter.

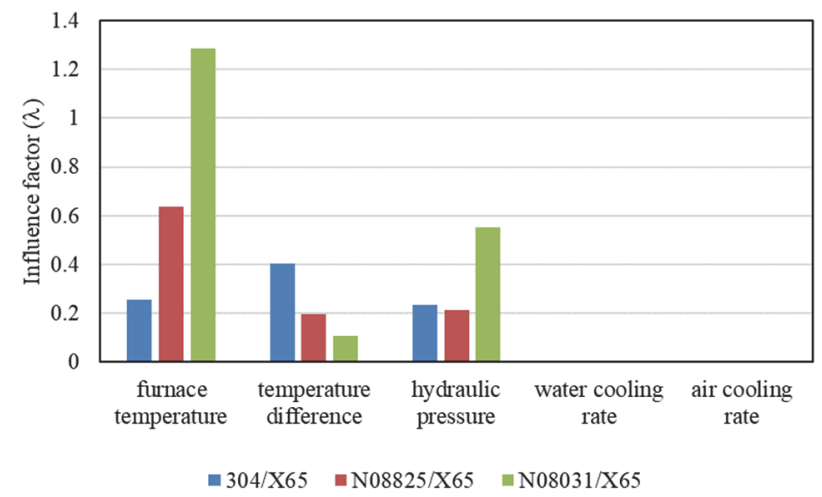

Figure 12 Influence factor of each parameter to the residual contact pressure of corrosion resistant pipes for different liner materials

The influence factors for each parameter are displayed in Fig. 12. Results reveal that both the water and air cooling rates have negligible influence on the residual contact pressure for all the material pairs. Temperature difference has the largest influence for the material pair 304/X65. However, for the material pairs N08825/X65 and $\mathrm{N} 08031 / \mathrm{X} 65$, the residual contact pressure is most sensitive to furnace temperature. 


\section{CONCLUSIONS}

In this study, finite element analysis of the thermalhydraulic expansion manufacturing process of corrosion resistant pipes was conducted, and the simulation results were verified by comparison with the analytical predictions and simulation results proposed by Focke et al. [14]. Furthermore, the sensitivity of the residual contact pressure between the liner and the outer pipes, to the different process parameters for three material pairs was investigated.

Among the analyzed process parameters, furnace temperature, temperature differential, and hydraulic pressure are shown effective, while the water and air cooling rates have negligible influence on the residual contact pressure. When 304 is used as the liner material, temperature difference has the largest influence factor. Thus, under proper furnace temperature and hydraulic pressure, reducing the hydraulic loading and unloading time durations during the manufacturing process as much as possible could be the effective way to obtain high residual contact pressure. In terms of the material pairs $\mathrm{N} 08825 / \mathrm{X} 65$ and N08031/X65, the furnace temperature is the governing factor. Therefore, determining and using the optimal furnace temperature for each material is the most effective method to obtain residual contact pressure. Besides, a larger hydraulic pressure also works to increase the residual contact pressure for the material pair N08031/X65.

\section{Acknowledgements}

This work was supported by The Petroleum Institute (PI), RIFP Project Code: 15323. Project Title: "Finite Element Analysis of Mechanically Sleeved CRA Pipes for Oil and Gas Pipelines", The PI support is greatly appreciated. Besides, the authors would like to thank Mr. Yannick Margani from ABAQUS for his help in the finite element analysis.

\section{REFERENCES}

[1] Yin, Z. F., Zhao, W. Z., \& Zhou, W. J. (2008). Corrosion behavior of SM80SS tube steel in stimulant solution containing $\mathrm{H}_{2} \mathrm{~S}$ and $\mathrm{CO}_{2}$. Electrochemica Acta, 53(10), 3690-3700. https://doi.org/10.1016/j.electacta.2007.12.039

[2] Kermani, M. B. \& Morshed, A. (2003). Carbon dioxide corrosion in oil and gas production: a compendium. Corrosion, 59(8), 595-603. https://doi.org/10.5006/1.3277596

[3] Zhang, Z., Taihe, S., \& Daiyan, S. (2005). Simulation research on the corrosion of downhole tubes in high production gas well. Natural Gas Industry, 25(1), 103-105.

[4] Xuesheng, W., Peining, L., \& Ruzhu, W. (2004). Estimation of residual contact pressure in hydraulically expanded CRAlined pipe. Chinese Journal of Mechanical Engineering, 17(1), 598-601.

[5] Fan, X., Wang, X., \& Chen, Q. (2020). Theoretical and numerical investigations of manufacturing bimetal CRAlined pipes using thermo-hydraulic forming. Journal of Thermal Analysis and Calorimetry. https://doi.org/10.1007/s10973-020-09699-4.

[6] Rommerskirchen, I. (2005). New progress caps 10 years of work with BuBi pipes. World Oil, 226(7), 69-70.

[7] Wang, X. S., Li, P. N., \& Wang, R. Z. (2005). Study of hydro-forming technology of manufacturing bimetallic
CRA-lined pipe. International Journal of Machine Tools and Manufacture, 45(4-5), 373-378.

https://doi.org/10.1016/j.jimachtools.2004.09.015

[8] Focke, E. S. (2007). Reeling of tight fit pipe. TU Delft, Delft University of Technology.

[9] Chen, W. C. \& Petersen, C. W. (1991). Corrosion performance of welded CRA lined pipes for flowlines. Offshore Technology Conference, 6-9 May, Houston, Texas.

[10] Yoshida, T. (1981). The development of corrosion-resistant tubing. Offshore Technology Conference, Offshore Technology Conference.

[11] Guo, T., Ozturk, F., Jarrar, F., \& Sheikh-Ahmad, J. Y. (2017). Analysis of Contact Pressure of Mechanically Lined Corrosion Resistant Alloy Pipe by Hydraulic Expansion Process. Journal of Pressure Vessel Technology, 139(2). https://doi.org/10.1115/1.4035314

[12] Zeng, D., Deng, K., \& Lin, Y. (2014). Theoretical and experimental study of the thermal strength of anticorrosive lined steel pipes. Petroleum Science, 11, 417-423. https://doi.org/10.1007/s12182-014-0356-z

[13] De Koning, A. \& Li, P. (2004). TFP and TFT back in town (Tight fit CRA lined pipe and tubing). Stainless Steel World, 1, 53-61.

[14] Focke, E. \& Nakasugi, H. (2004). The 2-Dimensional Modelling of the Manufacturing Process of Tight Fit Pipe (TFP). Fourteenth International Offshore and Polar Engineering Conference, International Society of Offshore and Polar Engineers.

\section{Contact information:}

\section{Jiansha DONG}

Department of Mechanical Engineering,

Khalifa University of Science and Technology,

Abu Dhabi, United Arab Emirates

E-mail: 1053637379@qq.com

\section{Fahrettin OZTURK}

(Corresponding author)

Turkish Aerospace Industries, Inc., Ankara, Turkey

Ankara Yıldırım Beyazıt University, Department of Mechanical Engineering,

Ankara, Turkey

E-mail: fozturk@ybu.edu.tr

\section{Ana NIETO}

Department of Mechanical Engineering,

Khalifa University of Science and Technology,

Abu Dhabi, United Arab Emirates

E-mail: nietober@gmail.com

\section{Tianye GUO}

Department of Mechanical Engineering,

Khalifa University of Science and Technology,

Abu Dhabi, United Arab Emirates

E-mail: 495303826@qq.com

\section{Firas JARRAR}

Department of Mechanical Engineering,

Khalifa University of Science and Technology,

Abu Dhabi, United Arab Emirates

E-mail: firas.jarrar@ku.ac.ae

\section{Jamal Y. SHEIKH-AHMAD}

Department of Mechanical Engineering,

Khalifa University of Science and Technology,

Abu Dhabi, United Arab Emirates

E-mail: jamal.ahmad@ku.ac.ae 